that an ordinary day worker only requires 2,500 calories. Dr. Chittunden says that he maintained the body weight under 1.000 calories a day while working in his laboratory though I believe he lost from 10 to 12 pounds at the beginning. If all this be true it seems to me that Dr. Coleman lias not established the fact that patients require such a large caloric diet as has been presented to us. I do not know whether he has the bowels moved-how often the contents are ejected from the body and how much ealoric value is lost-a point which I think is of value in a study of this kind. I have treated many cases on a low caloric value, often below 1,000 heat units per day.

During the past fiscal year I have had no deatls among fifty-one cases. I went on the principle enunciated by Munk that milk, egge, and meat products, such as soups and broths, are 97 to 99 per cent. absorbable. This left only 3 per cent or 1 per cent. of non-absorbable residue which had to pass through the bowels. If any patient can be placed on a diet and can absorb 98 per cent. of it, you can get a suflicient caloric value and you need not move the bowels every day. 'I'inese patients slould not be purged every day in your efforts to keep down distention. Distention is often due to paresis of the bowel rather than fermentation. With such a large absorp. tion of food, and with such a small residue there should be no occasion for purgation.

Dr. Warren Colmman, New York: I believe that the method of treating typhoid fever in Bellevue Hospital is essentially the same for all divisions, except in the matter of baths and feeding. Some of the visiting plyysicians employ the tubbath; some believe spongings sufficient. I believe that if we give enough food, hydrotlierapy becomes unnecessary in the majority of cases. The majority of the visiting physicians give more food than formerly, though $I$ believe that the second division is the only one in which the high calorie principle is fully carried out. The disappearance of the toxemiu is one of the most interesting results of giving sulficient food. We hatve observed it in many cases. Food which contains an indiges. tible residue should be excluded from the diet. I have used other foods than those on the chart but am not ready yet to recommend them. As to the care of the bowels, $I$ order a simple saline or soapsuds enema every morning. Usually this is all that is required. As stated in the paper, Dr. DuBois has studied the absorption of the high calorie diet during the last two years and has found that the food is almost completely absorbed. Very few studies have been made on metabolism in typlioid. Krauss published interesting observations in 1890. later work, until 1009, when Grafe's studies appeared, was apparently vitiated by errors of technic. Our own results have not been published. We have records of about 100 respiratory quotients, from which we have calculated the amount of heat produced by the patients in twenty-four hours. An amount of food just sufficient to cover the heat production will not protect a patient against nitrogen and weight loss. In other words, he will be partially starved. I should like to ask Dr. Graves why a typhoid patient should be starved. Why should he not be given the food he requires? Dr. DuBois' studies show that the patient digests it. I do not believe that a patient sufiering from any acute infective disease, except perhaps one affecting the alimentury tract locally, is benefited by starvation.

Simplest Method of Obtaining Blood-Serum.-Y. Sakaguchi pluces a sterilized stick or a piece of fine wire, with the bent end down, in the reagent glass or rentrifuge glass holding the blood. The stick or wire must be perfectly dry. The solid part of the blood as it coagulates will cling to the stick or wire and can be lifted out with it, thus leaving the serum alone behind. He states that in applying the Wassermann test over five thousand times, he has found this simple and easy method eflectual and reliable; the only point to be borne in mind is to wait until the clot hos entirely formed as otherwise the serum is left turbid and tests with it are liable to be misleading. He calls attertion to this method in ihe lisst Dermalologische.Wochenschrift, 1012, lv, 875.
THE ACTION OF SUBDURAL INJECTIONS OF EPINEPHRIN IN EXPERIMENTAL POLIOMYELITIS *

\author{
PAUL F. ClAARK, PJt.D. \\ NEW YORK
}

In 1903 Meltzer $^{1}$ showed that a subcutaneous injection of epineplrin caused a marked change in a local inflammation such as is produced by inoculating cultures of Staphylococcis aureus or a drop of turpentine into the soft tissues of the rabbit's ear. The eflect consists in a contraction of the actively hyperemic vessels at the periphery of the inflammatory area, while the more severely injured vessels within the inflamed focus remain unaffected. The contraction diminishes the transudation of fluid, the so-called lymph, from the hyperemic vessels, and thus reduces the local edema.

The lesions of poliomyelitis are associated with profound alterations of the blood-vessels, and are attended by transudation of fluid and emigration of white corpuscles from the altered vessels. The degree of vascular and interstitial changes varies in intensity in different cases and at different levels of the spinal cord. 'The vessels immediately within the focus of main injury are severely, while those at the margin of injury are often slightly affected. It is characteristic of lesions of certain cases of poliomyelitis in man and also in the monkey, although to a less extent, to be progressive, while in still other cases the lesions become quickly localized. This progressive tendency is most serious and alarming when the paralysis is of the ascending type and threatens the origin of the nerves controlling respiration and in especial those that supply the diaphragm. There is reason to believe that in the course of the ascent of the lesions slighter hyperemic states of the vessels attended with exudation precede the severer alterations of the vessels in which the perivascular cellular infiltration is extreme and the hemorrhagic eruptions large.

In view of the pathology of poliomyelitis as briefly outlined, the hyperemic vessels at the periphery of the lesions should be subject to the influence of the contracting effects of epinephrin. 'This response of the vessels should bring about a cessation of the exudation through which the dangers arising from the presence of an inflammatory edema on adjacent nerve-cells, which themselves are not the seat of direct injury, may be averted. Such an action might come to be very important and even life-saving in cases in which the nervecells that preside over the function of the phrenic nerves are involved. This temporary benefit could conceivably be converted into a permanent one by the cessution of the ascending lesion through the ordinary processes of limitation that are constantly encountered in cases of human poliomyelitis.

Moreover, the peculiar action of epinephrin on the vessels in the actively hyperemic area in contradistinction to the center of inflammation will suffice to indicate the nature of the pathologic process responsible for the ascent of the lesions. If the ascent arises from a continuous involvement of nerve-cells, epinephrin will be without any effect; but if it is produced by consecutive vascular involvement, then it may bring about a definite ameliorative action.

That epinephrin can be injected into the subdural space without danger to life has been shown through its

* From the Laboratorles of the Rockefeller Institute for Micaleal Research, New York.

1. Meltzer, S. J., and Meltzer, Clura : Jour, Med. Rescurch, 10031904, $x, 135$. 
employment in combination with cocain in the production of spinal anesthesia. Auer and Meltzer" have recently shown that the subdural injection of suitable quantities of epinephrin in the monkey does no harm and produces a characteristic action on the blood-pressure. This action consists in a slow but considerable rise and a gradual fall of the pressure. 'The duration of the rise is longer than after an intravenous injection, in some instances more than half an hour. The fall of blood-pressure occurs so slowly. at times that the original level is not reached during a period considerably over an hour. Incidentally it may be mentioned that Meltzer $^{3}$ has found that epinephrin is destroyed by the cerebrospinal fluid taken from patients with poliomyelitis.

At Dr. Meltzer's suggestion I have studied the action of subdural injections of epinephrin on monkeys paralyzed after intracerebral inoculations of the virus of poliomyelitis. 'The virus employed is one that invariably causes a fatal ascending paralysis or a rapidly fatal paralysis of respiratory centers in the medulla. In the former instance death results from the inclusion in the ascending process of the nerve-cells from which the phrenjc nerves arise. The animals selected were such as were alleady extensively paralyzed or were moribund and would have survived only a short time longer. They were limp, lay without movement except for superficial respiratory movements of the chest, and they were usually in a semiconscious or even unconscious state. The life of none of these monkeys was actually saved, but it was often greatly prolonged, ${ }^{5}$ while the effects of the epinephrin on the general condition of the dying animals were often remarkable. I shall now give in brief form a few illustrative protocols.

Protocol A.-Macacus rhesus. Nov. 9, 1911: Animal com. pletely prostrate, moribund; breatling is feeble, slow, almost entirely diaphrngmatic; only slight response to mechanical stimulation; eye reflexes slight. At $1: 30$ p. m., 1.5 c.c. of $l$ : 1,000 solution epinephrin injected subdurally. At 3 p. m.: Breatiing more rapid and deep; good response to mechanical stimulation; eye reflexes stronger. The animal appears bright. At 4 p. m.: In response to mechanical stimulation the left arn is moved inward and to some extent in the upward direction. The animal is bright and entirely conscious. The improvement in tho paralysis can be followed trom above downward. Animal turned on left side, the less paralyzed side. At 5 p. m.: No heart beat; pupils dilated; animul dying from asphyxia.

protocol B.-Macacus thesus. Feb. 19, 1912: Back, right arm, and leg paralyzed; prostrate; tremor of head; excitable.

Fobruary 20: Animal moribund: breathing feeble and shal. low; little tonus in arms or legs; semiconscious. At 10 a. m.: $1 . ;$ e.e. of $1: 1,000$ epinephrin injerted subdurally. No immediate eflect. At 10:30 a. m.: Consciousness has returned and respirations are accelerated. The animal eats part of a banana oflered. At 10:45 a. m.: Respirations deeper. At 11 a. m.: Marked increase in the tolns of arms and legs; some voluntary motion. At $12 \mathrm{~m}$.: Animal appen's bright, raises the head, and uses all of the limbs somewhat; respirations rapid but fairly deep. At 1 p. m.: Voluntary movements greater. At 3 p. m.: Marked improvement; respiration about normal. The animal takes food eagerly. At $4 \mathrm{p}$. $\mathrm{m}$.: The tonus in the arms is diminishing; nuimal still bright. At $4: 30$ p. m.: 4 c.e. of $1: 2,000$ epineplirin injected.

February 21: At 9 a. m.: The unimal is still bright and eats, but the muscles of the legs have lost in tonus. Usins

2. Auer, J., and Meltzer, S. J. : Proc. Soc. Exper. Blol. and Med., 1912, ix, 70 .

3. Meltzer, s. J. : Proc. Soc. Exper. Bjol. and Med., 1911, Ix, 27. 4. The brand of epinephirin used in the studies was the adrenalln chlorid of Parke, Davis \& Co.

5. See Flexner and Lewls (Jour. Exper. Med. 1910, xil, 22i) for the clinical bistory of cases of experlmental pollomyelitis in the monkey. right arm somewhat and left to a less degree. The condition persisted unchanged throughout the day.

February 22: Animal remains bright; has eaten a whole bannna. The extremities still show tonus.

February 23: Animal is growing weaker and appears iess bright. At $12 \mathrm{~m} .: 1$ c.e. of $1: 1,000$ epinephrin injected. No marked improvement.

February 24: Monkey developed a severe diarrhea durng the night. Weaker and less tonus in arms and nock. At 12:30 p. m.: 2 c.c. of $1: 2,000$ epinephrin injected subdurally. At 7 p. In.: Animal weaker. Diarrliea continues.

liebruary 25: The animal gradually failed and died in the morning.

Protocol C.-Hacacus rhesus. Feb. 24, 1012: Animal prostrate; little tonus in either legs or arms. 'The left leg and both arms respond slightly to mechanical stimulation; paraly. sis of the muscles of the neck; respirations feeble. At $1 \mathrm{p} . \mathrm{m}$.: 1.5 c.c. of $1: 1,000$ epinephrin injected subdurally. At the end of half an hour there is no noticeable change. Improvement sets in a little later, and at 7 p. $m$. the animal appears bright, the neck muscles stronger, and the respiration improved.

February 25: The paralysis of the limbs has increased; the respirations have become somewhat more shallow but are better than before the injection. A second injection of 1 c.e. of epineplrin was given, but without producing pronounced change.

February 26: The animal was found dead in the morning.

Protocol D.-Macacus rhesus. March 4, 1912: Arms and back weak but not completely paralyzed; the left arm and lecr weaker than the right. At 10 a. m.: 1 c.c. of epinephrin injected subdurally. At 6 p. m.: No evident improvement following the injection; the paralysis has progressed somewhat.

March 5: The animal is prostrate; back, neck, and four limbs all paralyzed, but not completely. At 10:15 a. m.: Epinephrin 1.5 c.c. injected. At 12 m.: The animal is brighter, eats; the muscles show increased tonus; respiration strong

March 6: This morning the respiration is somewhat irreg. ulnr, fifty-four to the minute; monkey cannot move arms or legs. The respiration is still fairly strong and both the intercostal muscles and the diapliragm are in use. At $11: 30$ a. m.: 1.5 c.c of epinephrin injected, and at 5 p. m., 1 c.c. of epinephrin injected, without producing any change in the extint of the paralysis of the extremities.

March 7: The respiration has become more feeble. At 12 m.: 1.5 c.c. of epinephrin injected. At 4 p. m.: The respiration is almost wholly diaphragmatic and is feeble and shallow; 1.5 c.c. of $1: 1,000$ epineplirin injected subdurally.

At 5 p. m.: Respiration shallow, expiration forced.

March 8: During the night the animal has improved; the respiration is not forced. At $11: 30$ a.m.: 1.5 c.c. of epinephrin injected; no obvious response to this injection. The animal is gradually becoming more feeble.

March 9: Respirations shallow and labored; expiration forced. At 10:30 a. m.: 1.5 c.c. of epinephrin injected. At 10:45 a. m.: Respirations become deeper and more rapid, but forced expiration still continues. At $5 \mathrm{p} . \mathrm{m}$.: The animal died.

The illustrative protocols given indicate that a sublural injection of epinephrin is capable of producing $\boldsymbol{a}$ murked change in the character of the paralytic phenomena in experimental poliomyelitis, although the effects are not equally striking in all cases. 'The general result was an improvement in the muscular tonus of the paralyzed muscles and in the respiratory movements. In some animals (Protocols A, B and D) the effects were striking, and a state of extreme flaccidity and unconsciousness with almost complete disappearance of reflexes was succeeded by one of tonus, of strengthened reflexes and of return of consciousness. Life was undoubtedly prolonged in these cases. In the other case (Protocol C) there is no definite proof that life was prolonged, and the symptoms were only moderately ameliorated. An examination of the two classes of cases would seem to show that the employment of the epinephrin relatively. 
early in the course of paralysis does not in the monkey inoculated intracerebrally with a highly active virus bring about an arrest of the progress of the disease. The life-saving action of the epinephrin is shown in the case of the moribund animals, in which life was prolonged either for several hours or for several days by the restoration of the failing respiratory function.

Finally, the effects of epinephrin in the experimental polionyelitis support the view that a state of hyperemia of the blood-vessels attended by an exudation of plasma and probably of cells also precedes the severer state of destruction of nerve-cells and interstitial tissue of the spinal cord. They indicate further that subdural injeetions of epinephrin in proper doses may be found capable of averting in human beings, the subjects of ascending forms of poliomyelitis, a latal issue through the involvement, in the extenting hyperemia and inflammatory edema, of the nerve-cells from which the phrenic nerves take their origin. Should this temporary interruption of the active pathologic process coineide with the natural limitation of the disease, even life may be spared. The experiments do not indicate that epinephrin itself contributes in any way to the promotion of the limitation of the lesions. Epineplrin is not a curative drug in the sense that it aets on and neutralizes the poliomyelitic virus. Any favorable effect that it may produce results from its action on the blood-vessels and the consequent control of exuclation.

\section{A RARE FINDING IN A SUSPECTED CASE OF PUL- MONARY TUBERCULOSIS}

\section{A. Flower, M.D., New York}

House Physlcian, Metropolitan Ilospital, New York City

During the month of November, 1911, a case was brought to the female medical ward of the Metropolitan Hospital. The patient was a colored womm, aged 57; her family history was negative. The patient's personal history was practically negative, with the exception of having had variola fourteen years ngo. Physical examination showed the very ear-marks of pulmonary tuberculosis; hence the patient was transferred to the service of Jr. W. S. Mills of the tubercular division. All laboratory manipulations failed to reveal the tubercle bacillus. Repented examination of the sputa, etc., proved negative for tubercle bacilli. Rales, distant bronchial breatling and, on pereussion, eavity formation, or what appeared to be such, could be plainly mapped cut.

The patient was treated in the regular rontine manner as are all patients of a similar malady in this hospital and she appeared to be improving, while her dyismea, at times, would show signs of disappearing.

The patient died Jan. 14, 1912. A post-mortem examination, performed, with my assistance, by Prof. John H. Larkin of Columbia University, revealed remarkable pathologic findings. Dr. Larkin, pathologist to the City Hospital for a number of years, believes this to be the second case of its kind from over 10,000 post-mortems that he has performed. In this instance, not even the ordinary and usual caleified and healed tuberculous areas that are so common in the average postmortem examinations were found. The primary condition was enclothelioma of the pleura with metastasis to most, if not all, of the viscera of the body.

Autopsy--Heart: Musculature in the left ventricle slowed a metastatic nodular growth measuring about $2 \mathrm{~mm}$. Lungs: Both apices werc transformed into lırd nodular masses; certain areas showed disintegration and that of the lower right lobe posteriorly showed nodular growth invading the pleura. No tuberculous areas were found in either lung. Liver showed a number of nodular metastatic growths in the active stage of disintegration. Kidneys showed several metastatic growths, the pelves of both being involved; other viscera, etc., gave negative findings.
Anatomic Diagnosis.-Primary endothelioma of the pleura with invasion of the upper lobe of the right lung, tumors showing active disintegration. Metastatic endothelioma of the liver and kidneys and metastatic growth in the septum of the left ventricle of the heart.

\section{A NEW TONSIL, FORCEPS}

Oscar Wilkinson, A.M., M.D., Washington, D. C.

When one considers how many instruments have been devised for the removal of tonsils it requires some temerity to ofier a new one, but I liave found the forceps illustrated below so very useful that I venture to offer it to the profession.

This forceps is angular, which enables the operator to grasp the tonsil in such a manner that his hand does not obscure the view of the field of operation. It is constructed so that the end does not bite a piece out of the tonsil but holds it firmlybetween the jaws, which enables the operator to make sullicient traction to pull the tonsil out of its bed, so that its out-

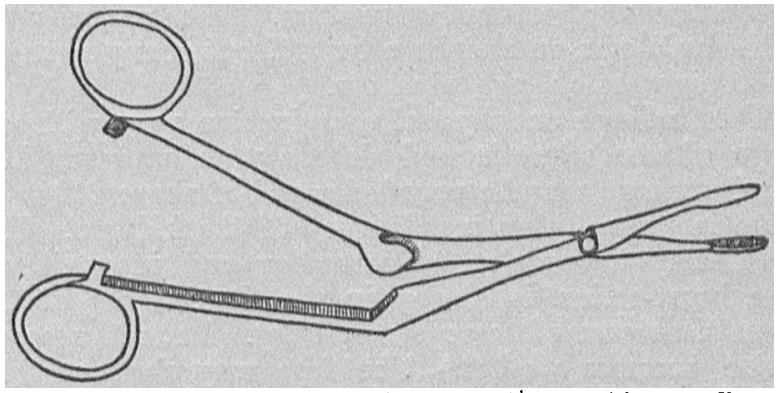

New tonsil forceps, as made by McKce \& Co., Washington, b. C.

line can be readily determined. I had it made with a catch in the handle, so that when the tonsil is once grasped there is no chanec of the grip on it being loosened.

When operating I use two of these instruments, and I find them of especial value in doing the tonsillectomy. By first grasping the tonsil near its upper portion the outline of its upper part can be brought into view, and by grasping the uppermost edge of the capsule with a second forceps it is an easy matter, with a dull dissector, to get in behind the tonsil, which everyone knows is the most difficult step in doing enucleation of the tonsil in its capsule.

1408 I Street N.-W.

\section{New and Nonofficial Remedies}

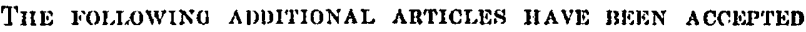
ny Jine Councis on Pliakmacy and Chemis'try of the AmerICAN Medical, Association. THEIR aCCep'tancli jas bEen BASIED LARGELY ON EVIDENCE SUPPIIED BY THE MANUFACTURHK OR HIS AGEN' AND IN PART ON INVESTIGATION MADE bY OR under the direction of the Council. Criticisms and colRECTIONS ARE ASKED FOR TO AID IN THE REVISION OF 'THE MATTLER Befole publication in the bOOK "NEW aND Nonofficiat. REM EDIEs."

Ting Counchl pesires pHysicians to Understand THAT THE ACCEPTANCE OF AN ARTICLE DOES NOT NECESSARILY MEAN A RECOMMENDATION, BUT 'HHAT, SO FAR AS KNOWN, IT COMPLIES Witri THE RULES ADOPTED BY TIE COUNCIL.

W. A. Puorner, Secretary.

\section{ARTICLES ACCEPTED FOR N. N. R. APPENDIX}

\section{H. K. Mulford Co., Pliiladelplia.}

Syrup of Quinine with Chocolatc.-Fach 100 C.c. Is suld to contuln In suspension, quinine sulphate $2.156 \mathrm{Gm}$. $(10 \mathrm{grains}$ in a fluidounce), chloroform as a preservattve 0.431 .Cc. (2 minims in a fuldounce) yerba santa (eriodictyon) a trace, in a syrup flavored with chocolate and vantllin.

with chocolate and vanthin. Ointment Cargentos and Iohthyol. - An olntment sald to consist of
enrgentos (colloldal silver oxide) 5 per cent. nnd fehthyol 5 per enrgentos (colloldal silver oxide) 5 per cent. and lchthyol o per
cent. in a hase consisting of petrolatum, with a small amount of cent. in a base consisting
ycllow wax, 80 per cent.

Prit, up In collapsible tubes. 